\title{
Relações entre a formação superior em Moda e os campos de atuação dos egressos
}

Relations between fashion higher education and the graduation's professional career

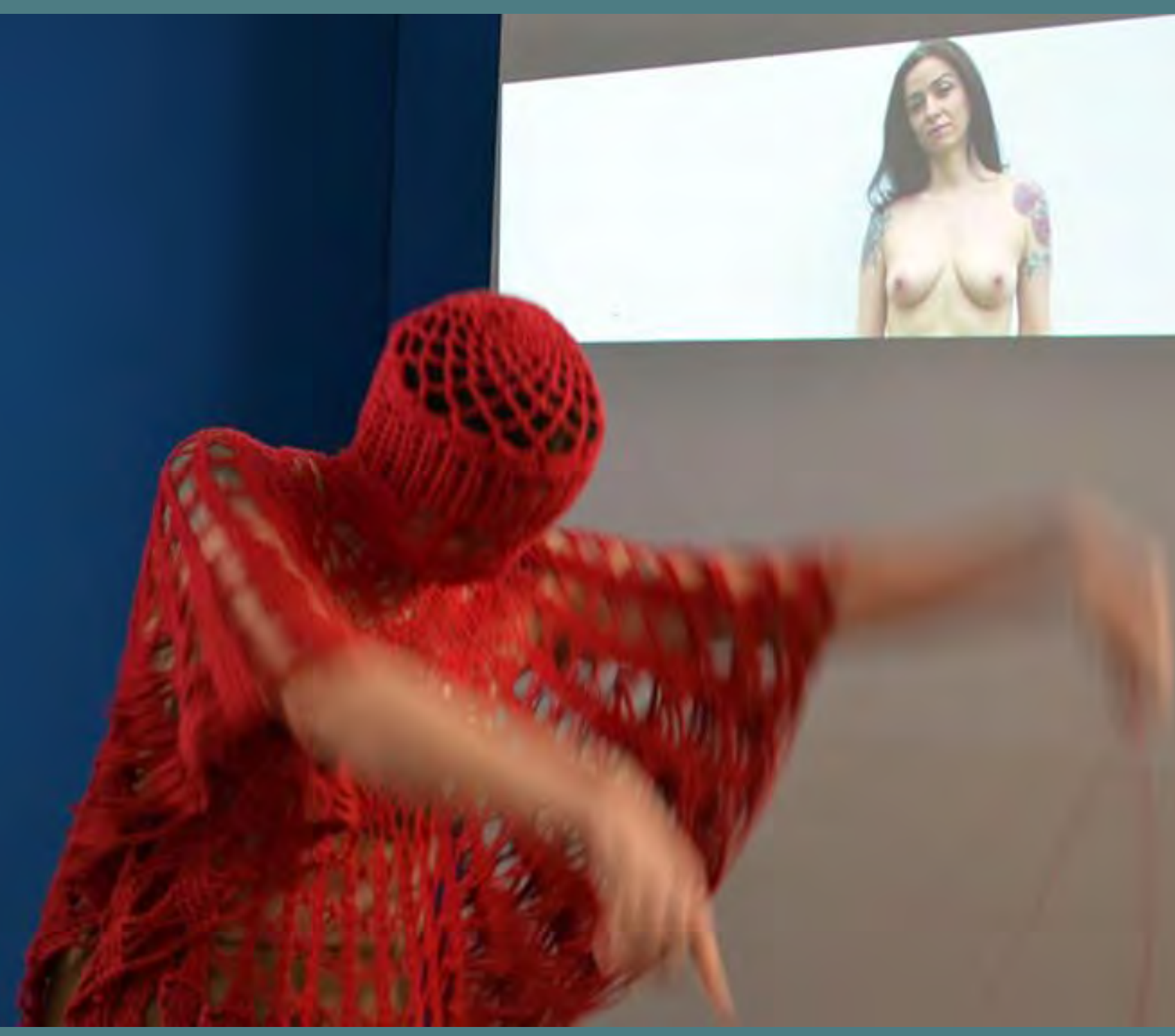




\section{Emanuella Scoz ${ }^{1}$}

ORCID: https://orcid.org/0000-0002-1651-1345

[resumo] 0 presente artigo tem como tema as relações entre a formação e o campo de atuação do profissional de moda. Foram analisados os percursos formativo e profissional e os campos de atuação dos egressos do ano de 2001 de um curso de bacharelado em Moda, em Santa Catarina, iniciado em 1997. Os dados da presente pesquisa foram gerados por meio do questionário, aplicado aos egressos (2001), dos quais os relatos dessa primeira turma auxiliam a compreender a proposta curricular e os diferentes contextos de formação daquele período histórico. Para compreender o currículo desse curso e seus cruzamentos com a atuação do profissional formado utilizou-se para geração de dados o Projeto de Viabilidade do Curso de Moda (1996) e a avaliação da entrevista com o coordenador do curso. A esses instrumentos foram utilizadas a análise temática e discursiva de Bardin (2016). Por meio dessas vozes, busca-se compreender como se dão suas relações profissionais a partir do currículo da graduação. Ainda como base teórica, utiliza-se Antunes $(1985 ; 2015)$ a fim de fundamentar as transformações vividas pelos estudantes diante das morfologias do mundo do trabalho durante a década de 2000.

\section{[palavras-chave] Curso superior. Moda. Trabalho. Egressos.}

[abstract] This research has as its theme the relations between the formation and the field of performance of the fashion professional. The training and professional trajectory and the fields of work of the graduates of 2001 from a bachelor of fashion course in Santa Catarina, started in 1997, were analyzed. The research analyzed reports from the first class of this course in order to understand the proposal curriculum and the different training contexts of that historical period and aims to analyze the fashion curriculum of this course and its relationship with the professional performance of graduates. Thus, through the voices of the graduates, we seek to understand how their professional relationships take place from the course curriculum. For this, thematic and discursive analysis by Bardin (2016) on curriculum documents of the Feasibility Project for the Fashion Course (1996), the analysis of the interview with the course coordinator and the answers to the questionnaire applied to the graduates (2001). Still as a theoretical basis, Antunes $(1985 ; 2015)$ is used in order to substantiate the changes experienced by graduates to the morphologies of the world of work during the 2000s.

[keywords] Fashion. Graduates. Higher course. Work.

Recebido em: 13-01-2020

Aprovado em: 30-04-2020

\footnotetext{
${ }^{1}$ Mestre em Educação pela Universidade de Blumenau (2019), Instituto Federal de Santa Catarina - Campus Gaspar. E-mail: emanuella_design@hotmail.com. Lattes: http://lattes.cnpq.br/3858787418552795.
} 


\section{Introdução}

A presente pesquisa tem como tema as relações entre a formação e o campo de atuação do profissional de Moda. Aqui foram analisados os percursos formativo e profissional dos egressos do ano de 2001 de um curso de bacharelado em Moda, fundado em 1997, de uma instituição de Blumenau, em Santa Catarina. 0 estudo avaliou relatos obtidos por meio de um questionário da primeira turma de formandos no mesmo, para investigar a proposta curricular e os diferentes contextos de formação daquele tempo histórico. Importante ressaltar que essa foi a primeira graduação de Moda de Santa Catarina a ser criada depois da Lei de Diretrizes e Bases da Educação (LDB/1996), portanto, as escolhas culturais estariam voltadas aos contextos locais.

No cenário econômico do Brasil da década de 1990, ocorreram mudanças no mundo do trabalho uma vez que, à época, o país abriu-se para os mercados internacionais e passou a sentir os efeitos da globalização, como o desemprego e a desigualdade social, reforçando sua condição de nação subdesenvolvida ao comparar-se com nações primariamente industrializadas (LENZI, 2000) como Alemanha e Itália, que já estavam em estágios mais avançados. Santa Catarina, por exemplo, possuía um modelo de desenvolvimento pautado na indústria (LENZI, 2000), o que foi possível observar no Plano Catarinense de Desenvolvimento (PCD) de 2006, assim como no investimento para que o curso de Moda auxiliasse na profissionalização do setor têxtil- vestuarista do Estado.

Durante a trajetória, os egressos vivenciaram a diversificação do segmento de moda e a reestruturação industrial no país. Em 2003, a Associação Brasileira de Estilistas (Abest) uniu esforços com a Agência Brasileira de Promoção de Exportações e Investimentos (Apex-Brasil) para a internacionalização do setor têxtil e do vestuário nacional, uma mobilização que influenciou no perfil multifacetado do especialista em moda (SILVA; NASCIMENTO, 2012).

Em novembro de 2006, foi criado o Programa Cultural para o Desenvolvimento do Brasil (BRASIL, 2006a), o qual abordava a moda como um segmento cultural, e depois surgiram as diretrizes do Plano Cultural da Moda, em 2013 (BRASIL, 2013a), que mencionava os campos institucionais, empresariais e criativos da moda.

Nesse sentido, a concepção de moda enquanto cultura foi impulsionada com o Projeto Cultural para o Desenvolvimento do Brasil (BRASIL, 2006a) e, posteriormente, influenciada pelo Plano Cultural da Moda (BRASIL, 2013a), ambos visando popularizar e democratizar a moda brasileira (BRASIL, 2013b). A Associação da Indústria Têxtil e de Confecção (Abit) participou desse processo e, a partir dele, surgiram os incentivos para os pequenos e médios produtores. No contexto econômico de Santa Catarina, durante a década de 2000, já se notava o estímulo do governo às micro e pequenas empresas (MPE) e ao microempreendedor individual (MEI) (PCD, 2006).

A história da formação do currículo de Moda no Brasil começou com os cursos técnicos, que formavam profissionais para a indústria, o que se inicia em Santa Catarina a partir do século XX. Para Borges e Lima (2015), o currículo da graduação teve origem no técnico, utilizando um conceito de moda vinculado ao vestuário. Para Mattos (2015), no Brasil, o reducionismo da concepção de moda origina-se da constituição fabril do trabalho com 
roupas e o surgimento dos cursos superiores ocorre a partir da década de 1990, motivado, em parte, pela demanda do setor têxtil-vestuarista por profissionais aptos a competirem no mercado externo.

A partir dessa breve contextualização, ressaltamos que a presente pesquisa visa compreender o currículo de Moda e seus cruzamentos com a atuação profissional do egresso, buscando, nas suas vozes, compreender as relações de trabalho estabelecidas desde o currículo do curso superior. Para isso, serão apresentadas algumas informações sobre a moda enquanto construção identitária no Brasil e sobre a moda inserida no contexto têxtil de Santa Catarina, as características da proposta curricular em sua primeira versão, bem como o percurso formativo dos profissionais e suas áreas de atuação depois da conclusão do curso, em 2001.

Dessa maneira, os instrumentos que utilizamos para o levantamento de dados foram o Projeto de Viabilidade do Curso de Moda, de 1996, uma entrevista semiestruturada com o coordenador do curso, o qual foi o proponente do projeto durante a década de 1990, e relatos dos egressos obtidos por meio de questionário. A técnica de estudo utilizada foi o exame do conteúdo de Bardin (2016), a análise temática e a do discurso. Em relação à proposta curricular do curso de Moda, nós a observamos com base nos contextos citados por Sacristán (2000), que considera o currículo uma construção histórico-social e, portanto, complexo e carregado de simbolismos.

O questionário foi aplicado aos egressos da primeira turma do curso de Moda da instituição investigada que se iniciou no segundo semestre de 1997. Dos 40 estudantes, 27 completaram a graduação nos quatro anos de duração mínima e se formaram em 2001. O contato com eles foi feito com autorização da Divisão de Registro Acadêmico (DRA) da universidade pesquisada. Dos 27 concluintes, conseguimos contatar 16 deles e obtivemos apenas oito respondentes, que são representados com nomes fictícios de personalidades da moda do Brasil.

Importante ressaltar que a pesquisa tem caráter qualitativo, logo, a amostra não representa o pensamento de todos os formandos, mas os excertos de suas trajetórias individuais trouxeram informações que nos ajudaram a compreender o currículo do curso de moda e suas relações com a atuação profissional.

Quanto às ligações entre os campos de atividade acessados pelos egressos e a formação curricular da graduação, foram identificadas mudanças no comportamento econômico global e regional, bem como no mundo do trabalho durante a trajetória dos profissionais. Assim, com esta pesquisa, esperamos colaborar para a compreensão da aplicabilidade do currículo do curso de Moda ao mundo do trabalho, diante das transformações relatadas pelos entrevistados, uma vez que se estamos tratando de acontecimentos que perpassam a economia, a cultura e a educação desde o início do século XXI.

\section{A moda e o processo de construção identitária}

Para Guimarães (2008), a moda enquanto cultura passou a vigorar no Brasil desde a década de 1980 com papel decisivo na construção de identidades e de consumo. A partir do momento que passou a ser compreendida como cultura, surgiram novas dinâmicas produtivas, organizacionais e criativas para o setor, considerando-se que "a Moda não só dá conta 
de certa estruturação simbólica própria de uma determinada cultura, mas gera cultura" (CIDREIRA, 2010, p. 245), o que faz o termo "moda" multidisciplinar.

As transformações sociais do fim do século XX, no trabalho e na cultura, propiciaram que conhecimentos além da produção, como os de consumo, adentrassem as esferas componentes do sistema de moda no Brasil durante a década de 1980. Para Baudrillard (1995), a moda é percebida em sua relação com os significados culturais, bem como com os estudos dos campos da economia, da sociologia, da semiologia e da filosofia. A moda também é foco de análise nos campos da psicanálise e da psiquiatria em função das relações "inconscientes que os sujeitos estabelecem com o vestir" (SANT'ANNA, 2016, p. 82).

0 mundo do trabalho e as teorias estudadas no curso superior formam um conjunto que se expande na criação de conhecimentos para a formação profissional. No Brasil, foi durante o século XX que a confecção do vestuário representou a produção mais importante do país (MATTOS, 2015). Em Santa Catarina, a política de desenvolvimento permitiu que especialmente a região de Blumenau se mantivesse por muito tempo como polo industrial têxtil, disseminando não só a cultura da industrialização, mas também a da produção de tecidos e a do empreendedorismo.

Santa Catarina se constituiu de uma política de colonização, povoada a partir do século XIX por culturas europeias, muitas delas já industrializadas. A imigração alemã para o Sul do Brasil ocorreu como um projeto da monarquia para a independência política do país. Em 1875, buscando terra e liberdade, foram para Santa Catarina colonos alemães e italianos e, em 1880, houve a maior concentração de tecelões no Estado. Logo após, a política de substituição das importações do Brasil entre as duas Grandes Guerras Mundiais "fez a produção industrial brasileira alcançar o auge" (KOHLHEPP, 2008, p. 208).

Influenciado pelo ideal positivista, o Brasil teve como consequência o ensino com foco na qualificação de mão de obra para o trabalho fabril. Por causa disso, e também pelo aumento populacional, em 1909 surgiram os primeiros cursos de ensino técnico em Santa Catarina. Em 1937, em função de uma nova legislação, as escolas de aprendizes artífices transformam-se em liceus para propagar o ensino profissional, atendendo às necessidades das indústrias em expansão. Em 1942, foi criado o Serviço Nacional de Aprendizagem Industrial (Senai) com a missão de "formar profissionais para a incipiente indústria nacional" (SENAI, 2018).

Ao surgirem as primeiras graduações em Moda no país, já havia uma concepção de curso estruturada em escolas técnicas com um modelo formal de sala de aula e aulas práticas em laboratório, entendendo a moda em sua relação com o vestuário e propondo um conceito de moda de "fora", que não se aplicava à demanda industrial nacional, e uma moda de "dentro", a qual necessitava seguir certos padrões produtivos. Assim, o primeiro curso superior de Moda do Brasil foi criado em 1987, na Faculdade Santa Marcelina, em São Paulo, e implementado em 1988.

Em Santa Catarina, apenas a partir da década de 1990 surgiriam os bacharelados em Moda: o da Universidade do Estado de Santa Catarina (Udesc), em 1996, e o com habilitação em Estilismo Industrial da Universidade Regional de Blumenau (FURB), em 1997. Para Lima e Moraes (2013), o lançamento dos cursos superiores em Moda deu-se pela necessidade do aquecido setor têxtil. Borges (2017), igualmente identifica o crescimento industrial e a aber- 
tura da economia brasileira para o mercado externo como impulsionadores da proliferação de graduações de Moda.

Já para Baltar, as mudanças na estrutura da economia brasileira durante a década de 1990, "com pouco investimento e lento aumento da produção, repercutiram negativamente no mercado de trabalho assalariado, criando eliminação dos postos de trabalho", ao mesmo tempo que foi percebido aumento de novas estruturas de trabalho (BALTAR, 1990) em igual número ao da eliminação dos postos de trabalho. Dado que corrobora a afirmativa de Antunes acerca das transformações no mundo do trabalho.

Durante a década de 1990, o setor de moda reinventava-se: trabalhos acadêmicos, instituições e empresas tratavam da "dimensão histórica, fenômeno midiático, o mercado editorial, a ampla cadeia produtiva, as inovações da tecnologia têxtil e dos processos de comercialização" (BONADIO; MARINHO; WAJNMAN, 2010, p. 2) ao mesmo tempo que os "eventos que assumiram dimensão internacional e que projetaram criadores e suas grifes para além das fronteiras nacionais" (BONADIO; MARINHO; WAJNMAN, 2010, p. 2) tentavam minimizar os danos causados pela reestruturação produtiva da década anterior.

As graduações em Moda tornam-se, paulatinamente, um mercado em expansão no país pela própria emancipação do capitalismo no mundo, alinhando-se aos contextos sociais vigentes. Em 1994, a “[...] liberalização das regras de credenciamento de cursos superiores, somada ao engessamento do setor público, permitiu uma expansão sem precedentes de cursos, faculdades e universidades particulares por todo o país" (BONADIO; MARINHO; WAJNMAN, 2010, p. 3).

Ainda durante a década de 1990, as novas formulações do trabalho demonstram ser complexas, heterogêneas e com ritmos de processos intensos (ANTUNES, 2015). Uma vez que a globalização afetou profundamente as questões econômicas, obrigando à flexibilização do trabalho e à criação de novos modelos para a obtenção de renda, ela mostrou-se mais difícil em sociedades semiperiféricas como o Brasil (SANTOS, 2002), afastado da concorrência global, cujo desenvolvimento econômico equiparava-se ao tecnológico.

Em Santa Catarina, por exemplo, houve a ruptura do modelo tradicional das indústrias locais (LENZI, 2000). O Vale do Itajaí constituiu-se como um polo industrial que, mesmo com atrasos estruturais, como defasagens no acesso à comunicação e à internet, durante a década de 2000 já havia se estabelecido no mercado internacional. Com a globalização, surgiu o desafio de manter a concorrência, buscando a capacitação do profissional do vestuário e o aperfeiçoamento dos conhecimentos de mercado e de consumo. A moda, assim, foi inserida nas empresas têxteis como meio para mantê-las no mercado global.

Conforme Antunes (2015, p. 185), a "mundialização e globalização do capital, no conjunto de países do Terceiro Mundo, especialmente aqueles intermediários, dotados de um significativo parque industrial" demandou às indústrias reinventarem-se para permanecer competitivas, uma vez que o mundo do trabalho e os seus desafios estavam globalizados, transnacionalizados e internacionalizados.

Para o Brasil, que tinha defasagem tecnológica em relação às nações primeiramente industrializadas (LENZI, 2000), isso significou flexibilizar as relações trabalhistas, levando ao crescimento dos ramos de serviços, dos setores terceirizados e de incentivos à criação de micro e pequenas empresas (MPE) e de microempreendimentos individuais (MEI), como reflexo do avanço do capitalismo (ANTUNES, 1995). 
De acordo com o Plano Catarinense de Desenvolvimento (2006), Santa Catarina investia em tecnologia desde a década de 1990, diversificando os arranjos produtivos e avançando em serviços. Esse fato pode ser corroborado por meio do acesso aos dados da pesquisa do Serviço Brasileiro de Apoio às MPE (SEBRAE, 2018), que indicam o aumento do MEI em Santa Catarina em cerca de 60\% de 2013 a 2015, o segundo maior aumento desse tipo de empreendedorismo no Brasil.

Não só essas questões econômicas e políticas do mundo do trabalho modificaram a relação entre o currículo do bacharel em moda e o acesso aos campos de atuação na área da moda, mas também mudanças políticas da área no Brasil. No início da década de 2000, concomitantemente às atividades do Programa Cultural para o Desenvolvimento do Brasil (BRASIL, 2006), que auxiliava na organização política e profissional, a moda aparece integrada ao Programa Cultura Viva ${ }^{2}$ para a construção de uma rede colaborativa de produtores de cultura com o intuito de criar ações para a sua valorização.

Por meio dessas mudanças, na maioria estruturais, percebemos que a trajetória profissional dos egressos da primeira versão curricular do curso de Moda da instituição pesquisada pode ter sido conturbada por diversos fatores divergentes, ou seja, de um lado a formação fabril para produtividade e, de outro, políticas de descentralização produtiva e investimentos na moda inter e multidisciplinar.

\section{Caracterização curricular}

O cenário histórico, político e econômico visto até o momento demonstraram ser influências da formação do curso de Moda, o que indica que o currículo é um campo de lutas que sofre influências de circunstâncias e de instâncias reguladoras (SACRISTÁN, 2000). Nas análises feitas, foi possível observar tais influências na formação curricular do curso de Moda em questão, ainda recente no Brasil, como a dificuldade em encontrar professores formados na área e aptos a lecionar ou a interferência política local exercida em função do contexto industrial têxtil da região.

O projeto do bacharelado em Moda estudado acena que as indústrias de confecção precisavam buscar meios de competir globalmente, uma vez que o Vale do Itajaí representava o segundo polo têxtil do mundo. Ao planejar o curso de Moda, previa-se ter profissionais com conhecimentos técnicos de produção para que essas empresas pudessem concorrer em produtividade, em estilo e em estética (PROJETO, 1996).

0 perfil do egresso estava voltado para criação, estilo e pesquisa de tendências. Além disso, a graduação proporcionava uma visão ampla do processo produtivo do vestuário, permitindo a incorporação dos conceitos de Moda nas indústrias da região. Com essa proposta, o objetivo de ensino atentava para o mercado regional de malharias, assessoria de moda, produção artística, indústrias e seus complementos, lojas, vitrinismo, feiras, eventos e publicações, abrangendo um amplo mercado de Moda, ainda que "o curso tenha o foco no processo produtivo, para trabalhar em escala industrial” (COORDENADOR, 2019), visando a demanda local.

Programa do Governo Federal iniciado em 2004, torna-se uma Política de Estado ao virar a Lei 13.018, em 2014. 
Nesse sentido, havia poucas formações em Moda no Brasil no século XX e o projeto do bacharelado em questão indica que, no fim desse século, existiam cursos voltados à profissionalização para o setor têxtil de confecção, com perfil para atelier fashion, que não representava a necessidade das indústrias da região (PROJETO, 1996). Isso justificava, assim, a necessidade de uma graduação em Moda que formasse profissionais para indústrias de pequeno, médio e grande porte, ou seja, mesmo com foco "regional, como as empresas locais estão em termos de competitividade, muito parecidas com o mercado internacional, os nossos alunos são capacitados para trabalhar em qualquer lugar do mundo" (COORDENADOR, 2019).

Dessa forma, a versão final do Projeto de Viabilidade do Curso apresenta a matriz curricular conforme o quadro 1.

QUADRO 1 - ESTRUTURA CURRICULAR

\begin{tabular}{|c|c|c|}
\hline \multicolumn{2}{|c|}{ ÁREA COMUM } & ÁREA PROFISSIONALIZANTE \\
\hline FORMAÇÃO GERAL & FORMAÇÃO BÁSICA & ÁREA ESPECÍFICA \\
\hline Informática 60 h/aula & Administração 60 h/aula & Fotografia $90 \mathrm{~h} /$ aula \\
\hline Sociologia $60 \mathrm{~h} / \mathrm{aula}$ & Indumentária 120 h/aula & Confecção 840 h/aula \\
\hline $\begin{array}{l}\text { Met. e técnicas de pesquisa } \\
30 \mathrm{~h} / \text { aula }\end{array}$ & Economia $60 \mathrm{~h} /$ aula & Desenho 300 h/aula \\
\hline Relações humanas 60 h/aula & Ética 30 h/aula & Custos $60 \mathrm{~h} /$ aula \\
\hline Português 60 h/aula & Direito $30 \mathrm{~h} /$ aula & Mercadologia $60 \mathrm{~h} /$ aula \\
\hline Matemática 60 h/aula & Tecnologia têxtil $90 \mathrm{~h} /$ aula & $\begin{array}{c}\text { Estágio supervisionado } \\
180 \mathrm{~h} / \text { aula }\end{array}$ \\
\hline Administração 60 h/aula & Cultura brasileira $60 \mathrm{~h} /$ aula & \\
\hline Língua estrangeira 120 h/aula & Fund. da linguagem 345 h/aula & \\
\hline $510 \mathrm{~h} / \mathrm{aula}$ & $795 \mathrm{~h} /$ aula & $1530 \mathrm{~h} /$ aula \\
\hline
\end{tabular}

FONTE: Elaborado pela autora, baseado em PROJETO (1996).

A matéria Fundamentos da linguagem possui quatro disciplinas: Estudo da cor, com 45 horas-aula; Desenho artístico IV, com 60 horas-aula; Desenho de modelo vivo III e IV, com 120 horas-aula; e Laboratório de criatividade, com 120 horas-aula. A matéria de Confecção tem a maior carga horária e abarca sete disciplinas: Tecnologia de costura, com 120 horas-aula; Tecnologia da confecção I, II, III, IV, com 240 horas-aula; Modelagem industrial I e II, com 120 horas-aula; Estilo I e II, com 150 horas-aula; Planejamento e desenvolvimento de coleção, com 60 horas-aula; Normalização e qualidade industrial, com 60 horas-aula; e Produção de Moda, com 90 horas-aula. É possível perceber que a área específica, destinada à formação profissionalizante, tem a maior carga horária mesmo com o menor número de matérias do que a área comum. 
Percebemos, assim, que a proposta curricular do curso foi constituída a partir do campo prático e do campo teórico (SACRISTÁN, 2000). Esses contextos nos ajudaram a categorizar os componentes do currículo e, ao analisarmos os ementários, nós os agrupamos em quatro categorias das quais duas referem-se ao contexto da prática e duas ao teórico, conforme os quadros 2 e 3 .

QUADRO 2 - CONTEXTO TEÓRICO

\begin{tabular}{|c|c|c|c|}
\hline \multicolumn{2}{|c|}{ CATEGORIAS } & \multicolumn{2}{c|}{$\begin{array}{c}\text { COMPONENTES CURRICULARES } \\
\text { HORAS }\end{array}$} \\
\hline $\begin{array}{c}\text { Criação, cultura e } \\
\text { linguagem }\end{array}$ & $\begin{array}{c}\text { Concentra os conhecimentos teóricos sobre Moda } \\
\text { relacionados com o mundo do trabalho e que não } \\
\text { tinham aplicação direta nos sistemas produtivos } \\
\text { têxtil, de vestuário e fabril. }\end{array}$ & $\begin{array}{c}\text { Estudo da Cultura Brasileira; História } \\
\text { da Indumentária I; História da } \\
\text { Indumentária II; } \\
\text { Laboratório de Criatividade I; } \\
\text { Laboratório de Criatividade II; Estilo I; } \\
\text { Produção de Moda; Fotografia e Vídeo. }\end{array}$ & $\begin{array}{c}615 \\
\mathrm{~h} / \mathrm{aulas}\end{array}$ \\
\hline $\begin{array}{c}\text { Profissional } \\
\text { pleno }\end{array}$ & $\begin{array}{c}\text { Compreende conhecimentos teóricos aplicados ao } \\
\text { mundo do trabalho que diferenciavam o currículo } \\
\text { técnico do superior. }\end{array}$ & $\begin{array}{c}\text { Ética; Inglês V; Inglês VI; Técnica de } \\
\text { Redação; Met. do Trabalho Acadêmico. }\end{array}$ & $240 \mathrm{~h} /$ aulas \\
\hline
\end{tabular}

FONTE: Elaborado pela autora (2019).

QUADRO 3 - CONTEXTO PRÁTICO

\begin{tabular}{|c|c|c|c|}
\hline CATEGORIAS & CONCEITOS & COMPONENTES CURRICULARES & $\begin{array}{l}\text { TOTAL DE } \\
\text { HORAS }\end{array}$ \\
\hline $\begin{array}{c}\text { Sistema } \\
\text { produtivo têxtil } \\
\text { do vestuário e } \\
\text { fabril }\end{array}$ & $\begin{array}{l}\text { Compõe-se de conhecimentos sobre sistemas } \\
\text { e processos industriais de produção que } \\
\text { tinham aplicação no segmento produtivo } \\
\text { têxtil-vestuarista, como } \\
\text { processos industriais, produção, maquinário } \\
\text { e gestão de equipes, visando a eficácia e a } \\
\text { eficiência dos processos fabris e da gestão } \\
\text { de produto; softwares e ferramentas do } \\
\text { sistema industrial, tecnologias e processos } \\
\text { produtivos e demais práticas que visavam os } \\
\text { processos de produção fabris. }\end{array}$ & $\begin{array}{c}\text { Administração; Administração na Confecção; } \\
\text { Informática Básica; } \\
\text { Matemática Básica; Psicologia Organizacional; } \\
\text { Sociologia do Trabalho; Direito do Consumidor; } \\
\text { Economia Brasileira; } \\
\text { Tecnologia Têxtil I; Tecnologia Têxtil II; } \\
\text { Aplicação Gráfica na Moda; Custos; Desenho de } \\
\text { Moda I; Desenho de Moda II; } \\
\text { Desenho Têxtil I; Desenho Têxtil II; Estilo II; } \\
\text { Marketing na Moda; Modelagem Industrial } \\
\text { I; Modelagem Industrial II; Normalidade } \\
\text { e Qualidade Industrial; Planejamento e } \\
\text { Desenvolvimento de Coleção; Tecnologia da } \\
\text { Confecção I; } \\
\text { Tecnologia da Confecção II; Tecnologia da } \\
\text { Confecção III; } \\
\text { Tecnologia da Confecção IV; Tecnologia de } \\
\text { Costura Mod. I; } \\
\text { Tecnologia de Costura Mod. II. }\end{array}$ & $1680 \mathrm{~h} /$ aulas \\
\hline $\begin{array}{l}\text { Práticas } \\
\text { artísticas }\end{array}$ & $\begin{array}{l}\text { Concentra conhecimentos sobre práticas } \\
\text { artísticas aplicados ao mundo do trabalho, } \\
\text { mas que não tinham relação com o sistema } \\
\text { produtivo e não estavam relacionadas às } \\
\text { teorias de moda. }\end{array}$ & $\begin{array}{c}\text { Desenho Artístico IV; } \\
\text { Desenho de Modelo Vivo III; } \\
\text { Desenho de Modelo Vivo IV. }\end{array}$ & $120 \mathrm{~h} /$ aulas \\
\hline
\end{tabular}

FONTE: Elaborado pela autora (2019).

Assim, na análise do quadro 3, identificou-se uma predisposição para o contexto da prática fabril em detrimento da teoria. Analisando-se o projeto da graduação em Moda, percebeu-se uma polarização conceitual entre a moda de ateliês e a moda de fabricação em grande escala, ou seja, em função da escolha pela fabricação em grande escala, houve a seleção de teorias que melhor se adaptassem à realidade local. Sobre esse ponto, cabe fazer 
uma ressalva quanto à concepção de moda relacionada ao vestuário nos currículos. Essa percepção trata de um conceito comum à moda no século XX, de criar peças e coleções de roupas e acessórios. Ao entrar no século XXI, no entanto, o próprio termo moda atinge novas proporções conceituais, muitas delas advindas do desenvolvimento do Projeto Cultural para o Desenvolvimento do Brasil, que agregou e validou a moda como cultura. E, para estudar a cultura, é necessário entender o domínio do simbólico dentro e no centro da vida em sociedade (HALL, 2016). 0 sentido criado em uma prática cultural é o que permite "cultivar a noção de nossa própria identidade" (HALL, 216, p. 21), tanto coletiva quanto individual. Não bastando o estudo dos hábitos de vestir e comprar, mas também dos movimentos sociais e das representações linguísticas e visuais dos símbolos criados e recriados diariamente nas diversas culturas. Essa condição torna complexo o trabalho do profissional de moda, uma vez que os valores são variáveis.

Dessa forma, a escolha cultural de um currículo de Moda está envolta em muitas instâncias reguladoras e, uma vez que a moda se trata de um sistema (SANT'ANNA, 2016) envolto por questões sociais, há dificuldades também em estabelecer um currículo sem se ter uma base em diretrizes curriculares mínimas específicas para a área.

\section{Percurso formativo dos egressos nos campos de atuação}

Com amostragem de oito respondentes, pudemos analisar o currículo uma vez que o questionário levava em consideração a percepção de cada um em relação ao curso e ao mundo do trabalho. A investigação foi composta por três blocos: 1 . caracterizar o perfil do estudante; 2. ênfases curriculares do curso de Moda e o percurso formativo dos egressos; e 3. relações entre o currículo e o campo de atuação.

Sobre o perfil do egresso, foi dedicado um pseudônimo de personalidades da moda para cada respondente a fim de manter o seu nome sob sigilo nesta pesquisa, conforme o quadro 4 a seguir.

QUADRO 4 - PERFIL DO EGRESSO

\begin{tabular}{|c|c|c|c|c|c|}
\hline EGRESSO & PSEUDÔNIMO & $\begin{array}{c}\text { IDADE NO } \\
\text { INGRESSO }\end{array}$ & $\begin{array}{c}\text { IDADE NA } \\
\text { FORMAÇÃO }\end{array}$ & $\begin{array}{c}\text { CIDADE ONDE MORAVA } \\
\text { QUANDO INGRESSOU NO } \\
\text { CURSO }\end{array}$ & $\begin{array}{c}\text { LOCAL ONDE MORA } \\
\text { ATUALMENTE }\end{array}$ \\
\hline 1 & Versolato & 19 & 24 & Blumenau & Blumenau \\
\hline 2 & Lino & 21 & 25 & Blumenau & Bstados Unidos \\
\hline 3 & Dener & 22 & 26 & Blumenau & Blumenau (Itália) \\
\hline 4 & Palomino & 18 & 23 & Blumenau & Blumenau \\
\hline 5 & Kalil & 20 & 24 & Brusque & Curitiba \\
\hline 6 & Coelho & 29 & 33 & Blumenau & Hamburgo (Alemanha) \\
\hline 8 & Zuzu & 21 & 26 & Blumenau & \\
\hline
\end{tabular}

FONTE: Elaborado pela autora (2019).

Observando o quadro acima, percebe-se que os ingressantes eram jovens e concluíram o curso no prazo médio de quatro anos. Das cidades em que os respondentes indicaram 
moradia, atualmente, todos residem em locais de representatividade têxtil, fabril, de indústria criativa ou em polos educacionais. Blumenau faz parte do cluster têxtil do Vale do Itajaí (MEYER-STAMER, 2000), Balneário Camboriú é conhecida por sediar vários cursos livres e instituições privadas de ensino de Moda, assim como Curitiba. A província de Como, na Itália, é um centro industrial ao lado de Milão, que faz parte da rota da seda (COMO, 2005), e Hamburgo, além de centros de ciência e pesquisa, possui considerável indústria criativa (PERFIL da ALEMANHA, 2018).

Das motivações sobre a escolha do curso, os egressos indicaram o seguinte:

\section{QUADRO 5 - MOTIVAÇ̃̃O "A"}

\section{INGRESSAR EM ÁREAS NÃO PRODUTIVAS E QUE ESTAVAM RELACIONADAS AO SETOR DE MODA}

Na verdade, eu sempre quis fazer Jornalismo, mas na época não tinha esse curso em Blumenau. Antes de ingressar em Moda, cursei P\&P por dois meses, mas vi que não seria feliz "vendendo". Fazendo Moda teria a possibilidade de talvez um dia atuar como jornalista de moda. Minha principal motivação era o estudo das razões pessoais de escolha de cada um por determinada vestimenta ou estilo. (VERSOLATO, 2019)

\section{INTERESSE EM ATIVIDADE PROFISSIONAL CRIATIVA. (ZUZU, 2019)}

Eu tinha uma predisposição mental para trabalhar com arte -a Moda me parecia um universo com maior chance de eu conseguir rentabilizar arte com mais facilidade. (PALOMINO, 2019)

FONTE: Elaborado pela autora (2019).

A fala do egresso Versolato (2019), como vemos acima, evidencia campos de atuação em moda variados e acessados com a formação inicial. As palavras de Palomino (2019) denotam a ideia de que a moda poderia fazer parte do universo artístico de forma mais rentável.

QUADRO 6 - MOTIVAÇÃO “B”

\begin{tabular}{|c|}
\hline PIONEIRISMO E INEDITISMO DO CURSO \\
\hline Interesse desde criança e pelo fato de ser um curso pioneiro. (LINO, 2019) \\
\hline Já trabalhava na área e buscava a graduação, e por ser o único na região. (KALIL, 2019) \\
\hline
\end{tabular}

Fonte: Elaborado pela autora (2019).

O fator geográfico pode ter contribuído para a escolha da graduação, como vemos no excerto da fala acima, uma vez que, naquele período, havia curso superior de Moda somente em Florianópolis, situada a 151 km de Blumenau.

QUADRO 7 - MOTIVAÇÃO “C”

\begin{tabular}{|c|}
\hline INSERÇÃO NO SETOR DA MODA - EXISTENTE OU DESEJADA \\
\hline Vontade de trabalhar com moda. (DENER, 2019) \\
\hline Na minha infância, os meus pais tiveram confecção, também por Blumenau ser um polo têxtil e eu ter resolvido voltar às minhas \\
raízes. (COELHO, 2019)
\end{tabular}

Fonte: Elaborado pela autora (2019).

Sobre a ênfase na formação em Moda, os egressos identificaram que ela era voltada para as questões de produção (técnica) e de gestão e apresentaram algumas justificativas 


\section{QUADRO 8 - JUSTIFICATIVA “A”}

\begin{tabular}{|c|} 
CONTEXTO PEDAGÓGICO-TECNOLÓGICO \\
\hline $\begin{array}{c}\text { O curso tinha sua grade curricular composta majoritariamente por disciplinas técnicas, e mesmo as de cunho mais social eram } \\
\text { trabalhadas sem grande profundidade. (VERSOLATO, 2019) }\end{array}$ \\
\hline Maioria das classes voltadas à tecnologia. (LINO, 2019) \\
\hline $\begin{array}{c}\text { Os professores que se destacavam eram os técnicos, isso influenciou no estilo de formação da turma. Quando o assunto era expandir } \\
\text { o conhecimento para temas sociais, comportamentais e de cunho global, os professores acabavam limitados às suas poucas } \\
\text { experiências e/ou a referências genéricas facilmente alcançadas em uma pesquisa on-line. (PALOMINO, 2019). }\end{array}$ \\
\hline
\end{tabular}

Fonte: Elaborado pela autora (2019).

Além disso, a maior carga horária alocava componentes curriculares técnicos e os que consideravam as teorias de Moda possuíam carga horária relativamente menor e muito conteúdo, o que provocava a sensação de superficialidade em relação às unidades curriculares com mais horas-aula. .

\begin{tabular}{|c|} 
QUADRO 9 - JUSTIFICATIVA “B” \\
FOCO INDUSTRIAL \\
\hline Foco na indústria. (DENER, 2019) \\
\hline A grade curricular privilegiava atender demandas do ramo têxtil existente na cidade e região. (ZUZU, 2019) \\
\hline Foco na forte indústria têxtil da região. (BUNDCHËN, 2019) \\
\hline Produção em massa é o foco e não o lançamento de moda. (COELHO, 2019) \\
\hline
\end{tabular}

Fonte: Elaborado pela autora (2019).

Inseridos nessa realidade, compreendemos que o contexto social e econômico vigente exigia, com certa urgência, preencher a demanda de profissionais de moda que compreendessem os processos fabris para a produção em grande escala. Os egressos estavam conscientes de que a região era um polo têxtil:

\begin{tabular}{|c|} 
QUADRO 10 - JUSTIFICATIVA “C” \\
MERCADO E EMPREGABILIDADE \\
\hline Por querer me adequar ao mercado local, visto que é muito mais industrial do que moda na época. (KALIL, 2019) \\
$\begin{array}{c}\text { Por estarmos num polo têxtil, grande criador de renda e onde a produção em massa é o foco e não o lançamento de moda (não somos } \\
\text { uma cidade que dita a moda, nós a seguimos }\end{array}$ ), faz-se necessário o conhecimento mais técnico, para se obter ganhos de produtividade, \\
redução de custos e melhores métodos de trabalho dentro dessa indústria. (COELHO, 2019)
\end{tabular}

Fonte: Elaborado pela autora (2019)

O fator competitividade é trazido pelo egresso Coelho (2019). Em sua fala, observamos que a inserção da moda nas indústrias acontece como uma inovação, que permitiu o reposicionamento das empresas locais nos mercados com ganho de eficiência ao abranger

\footnotetext{
3 Ver Sanches (2006).
} 
o ensino de gestão e produção. Das contribuições do curso e dos componentes curriculares, os profissionais indicaram o que se observa no quadro a seguir:

\begin{tabular}{|c|} 
QUADRO 11 - CONTRIBUIÇÃO “A” \\
CONTRIBUIU NA FORMAÇÃo PROFISSIONAL \\
\hline Entendo que o conjunto geral daquele primeiro currículo contribuiu para a minha formação. (LINO, 2019) \\
\hline Quase todas. (DENER, 2019) \\
\hline Todas as disciplinas serviram muito na minha vida profissional e particular. (BÜNDCHEN, 2019) \\
\hline
\end{tabular}

Fonte: Elaborado pela autora (2019).

Os componentes curriculares, dessa forma, foram importantes para a formação profissional dos egressos, assim como alguns deles, especialmente, tiveram mais relevância, conforme vemos abaixo:

QUADRO 12 - CONTRIBUIÇÃO “B”

\section{CAMPO PRÁTICO E CAMPO TEÓRICO}

História da Moda, desenhos técnicos, modelagem industrial, tecnologia têxtil e técnicas de estamparia. (PALOMINO, 2019)

Engenharia de produção e história da moda. (KALIL, 2019)

Modelagem, Costura, todas as disciplinas técnicas (na época, realizadas no Senai), desenhos técnicos. As disciplinas com base no estudo da evolução da moda também foram de grande valia. (COELHO, 2019)

História da Moda. (ZUZU, 2019)

Fonte: Elaborado pela autora (2019).

Assim, os egressos sugeriram, baseados em sua experiência profissional, processos de aprendizagem e novos componentes curriculares, a saber:

QUADRO 13 - SUGESTÃO “A”

\section{PROCESSOS DE APRENDIZAGEM DO CURRÍCULO}

Penso que deveria ser feito um direcionamento/divisão por áreas de interesse de atuação. Além das disciplinas básicas, comuns a todos os alunos, a partir do semestre X ou Y, haver a opção/ênfase para determinada formação.

Ex.: Modelagem: aulas mais avançadas (molde no papel e sistema + moulage). Produção de Moda: mais aulas de

foto, vídeo, vitrinismo, personal stylist e afins. Criação: foco na pesquisa e na criação propriamente ditas, além do aprimoramento em desenho técnico (mais importante na indústria que o desenho de croquis, por exemplo). Importante também o profundo conhecimento técnico (para ter noção de viabilidade na produção). (COELHO, 2019)

Além de qualquer grade, acredito que o curso deveria estar todo estruturado em projetos. Como eu estava atrasada, acabei fazendo vários semestres com a segunda e a terceira turmas e numa das fases fizemos um trabalho interdisciplinar com Planejamento de Coleção, Estamparia e outras disciplinas e foi muito legal! As disciplinas isoladas não fazem tanto sentido quanto um projeto. Amei fazer! (VERSOLATO, 2019)

Fonte: Elaborado pela autora (2019).

A fala de Coelho (2019), como vemos no quadro acima, por exemplo, remete-nos à ideia da necessidade de transformações no modelo de aprendizagem empregado. Segundo Sacristán (2000, p. 37), "no ensino universitário se destaca a adequação dos currículos ao 
progresso da ciência, de diversos âmbitos do conhecimento e da cultura, e à exigência do mundo profissional". A nova morfologia do mundo dos negócios considera a totalidade do trabalho social (ANTUNES, 1995), bem como sua precarização, com o surgimento de novos arranjos produtivos e da expansão das oportunidades empregatícias para o nível global, tornando complexa a estruturação curricular e trazendo novos desafios aos métodos tradicionais de ensino.

Para Sacristán (2000, p. 49), é "através da aprendizagem do currículo" que "os alunos se convertem em ativos participantes da elaboração de seu próprio saber, o que deve obrigá-lo a refletir sobre o conhecimento, incluindo o do professor". Nesse sentido, o método de ensino por projetos demonstrou, na fala do egresso Versolato (2019), o foco no aprendizado e na reflexão sobre a prática.

QUADRO 14 - SUGESTÃO “B”

COMPONENTES CURRICULARES PARA UM NOVO MUNDO DO TRABALHO

Estratégias de vendas de moda e mídias sociais. (KALIL, 2019)

Design de bolsas e calçados, e-business, administração da confecção e moulage. Algo como intercâmbios profissionais. (PALOMINO, 2019)

Custos, Produção da Coleção, Material gráfico (catálogo) etc., inclusive desfile, ou seja, um semestre no qual todas as disciplinas praticamente se unem. (BÜNDCHEN, 2019)

Negócios da Moda, História da Arte, Tecnologia, Sustentabilidade, Comunicação. (VERSOLATO, 2019)

Estágio em empresa do ramo, um semestre, pelo menos. Aprofundamento de disciplinas voltadas para as relações entre a indumentária e as ciências humanas. (ZUZU, 2019)

Gestão de pessoas e equipes, comunicação e semiótica. (DENER, 2019)

Fonte: Elaborado pela autora (2019).

Observamos, no quadro acima, que a necessidade de intercâmbios relatada por Palomino (2019) demonstra a urgência em pensarmos em um currículo de Moda internacionalizado. Dessa forma, percebemos que o perfil profissional, de certa forma, migrou de modo a somar os conhecimentos de moda às morfologias do mundo do trabalho do século XXI.

Os egressos relataram ter concluído cursos complementares, livres e de especialização. Para Palomino (2019), "na verdade, a graduação pouco contribuiu para minha construção profissional. Foram as especializações que me formaram". Sabemos da multidisciplinaridade das redes de trabalho com moda e isto se reflete nas dificuldades em associar conhecimentos diversos em um único currículo. Dessa forma, a reinterpretação dos conceitos de moda e da forma de lecionar, mencionados até o momento, poderiam minimizar a distorção entre o saber do profissional formado e as necessidades dos campos de atuação.

Os cursos acessados faziam parte das áreas de Marketing, Tendências, Moda, Gestão, Comunicação, Modelagem e Superfície e nos indicam aprofundamentos importantes para novos campos de atuação. Logo, as formações em Moda, para atender às demandas atuais, poderiam considerar as facetas culturais tais quais sistemas de conhecimento, de linguagens e de comunicação, formas de expressão estética, economia, estrutura social, organização como conjunto social em governos, conjuntos de valores e sentido histórico pelos quais evoluíram os aspectos culturais, e meios de sobrevivência e transmissão da realidade aos indivíduos (SACRISTÁN, 2000). 
Sobre as atuações profissionais dos egressos, elas encontram-se em consultoria de moda e estilo, designer, modelagem, branding e produção de eventos, pesquisa e docência, além de campos do conhecimento mais acessadas, como marketing e vendas, gestão de produtos e marcas e estilismo e desenvolvimento de produtos. 0 profissional Versolato, por exemplo, mudou de área ao completar a graduação, declarando não ter ingressado em campos de atuação relacionados ao curso de Moda, ou em cursos outros, finalizando sua participação nesta pesquisa já que não poderia responder aos questionamentos seguintes. A partir de então, o questionário seguiu com sete respondentes e não mais oito.

Além disso, os egressos relataram não terem tido dificuldades para acessar o mundo do trabalho, mas identificaram pouca prática, sugerindo, então, que fossem incluídas disciplinas como estágio supervisionado (COELHO, 2019) e outras de cunho mais prático, ainda indicaram algumas defasagens do segmento, como vemos a seguir:

QUADRO 15 - DIFICULDADE “C”

\section{DEFICIÊNCIAS NA RELAÇÃO CURSO X MUNDO DO TRABALHO}

Base acadêmica fraca e pouca procura por profissionais da criatividade na indústria têxtil da região. (PALOMINO, 2019)

Empregos mal pagos, atrofia da criatividade em prol de custos baixos (geralmente por centavos), forte concorrência por causa da abundância de cursos de Moda na região. (BÜNDCHEN, 2019)

O despreparo dos professores escolhidos para lecionar em nossa turma. Por exemplo, na matéria de custos, que deveria ser voltada para área de Moda. (KALIL, 2019)

Fonte: Elaborado pela autora (2019).

Na fala de Bündchen (2019), por exemplo, percebemos que o aumento de graduações em Moda nos anos 2000 interferiu na sua trajetória profissional. A afirmativa de Kalil (2019), por sua vez, demonstra a formação de professores ainda incipiente, uma vez que na década de 1990 havia poucas instituições com oportunidades que abrangessem todas às ramificações da cadeia têxtil e de moda.

\section{Relações das áreas de atuação com as áreas produtivas}

Ainda com base nos questionários, os egressos relataram ter feito contatos relativos à produção no nível local, internacional e nacional, estes em maior número de ocorrência, e mantiveram vínculos produtivos também no nível regional. Houve, ainda, contatos relativos à criação no nível local, internacional e nacional, estes também mais numerosos, assim como se observou contato profissional no nível regional.

Os dados levantados indicaram a existência de troca de informações sobre moda sem relação com setores produtivos e no nível local de forma mais expressiva do que os realizados regional e nacionalmente. Esses resultados podem ser indícios de uma cultura de moda que contém meios e profissionais para a execução de pesquisa de moda e, por sua vez, a existência de uma construção cultural da área com foco na identidade regional. Além disso, os dados indicaram o caráter internacional do mundo do trabalho e a globalidade característica da moda.

Sobre as empresas com as quais os egressos construíram vínculos produtivos e criativos, $43 \%$ delas são do setor de serviços, $43 \%$ da indústria, 14\% eram MEI e nenhuma era 
MPE. Ao considerarmos que os serviços podem incluir atendimento aos MPE, isso demonstra fragmentação e segmentação do setor, diversificação dos arranjos produtivos e, também, a precarização do trabalho, segundo Antunes (2015). Esses registros demonstram a existência de uma economia complexa e alinhada ao modelo econômico global.

0 percurso profissional dos entrevistados se deu, em $85,7 \%$ dos casos, na área de produção e gestão e, em $28,6 \%$ dos casos, nos segmentos de cultura, produção cultural e indústria cultural. Em sua trajetória profissional, os egressos reconheceram um campo prático focado em: a. processos produtivos; e b. campo teórico/prático de moda.

\begin{tabular}{|c|} 
QUADRO 16 - FOCO “A” \\
FOCO NOS PROCESSOS PRODUTIVOS \\
$\begin{array}{c}\text { O mercado sempre dá prioridade para produção e gestão, são e sempre serão essenciais para } \\
\text { os negócios, em especial o decadente mercado têxtil. (PALOMINO, 2019) }\end{array}$ \\
\hline Foco nos custos e na produção. (BÜNDCHEN, 2019) \\
\hline Desenvolvimento de coleções e modelagens. (COELHO, 2019) \\
\hline Cinco anos na área de moda trabalhando numa empresa que produzia para empresas baseadas nos EUA. (LINO, 2019) \\
\hline
\end{tabular}

Fonte: Elaborado pela autora (2019).

O projeto do curso delimitava o foco nos processos produtivos. Além do segmento industrial, os egressos relataram trabalhar com moda, tratando das concepções do seu campo teórico e com pesquisa científica:

QUADRO 17 - FOCO “B”

\begin{tabular}{|c|} 
CAMPO TEÓRICO/PRÁTICO DE MODA \\
\hline Sempre esteve mais ligada à indústria de moda. (KALIL, 2019) \\
\hline $\begin{array}{c}\text { Apesar de ter trabalho como desenvolvedora de produtos de moda, considero como } \\
\text { definitiva a carreira como pesquisadora acadêmica. (ZUZU, 2019) }\end{array}$ \\
\hline
\end{tabular}

Fonte: Elaborado pela autora (2019).

Sobre sua trajetória, por exemplo, Zuzu (2019) descreve: "Atuei como desenvolvedora de produtos em diversas empresas, todas localizadas na cidade de São Paulo. Após oito anos, passei a me dedicar à formação na pós-graduação, mestrado e doutorado na área de Design nas universidades Universidade Tecnológica Federal do Paraná e Universidade Federal do Paraná, e continuo os estudos" (ZUZU, 2019).

A trajetória do egresso Dener (2019) também demonstra progressão profissional, ascendendo a cargos de controle e gestão e até um empreendimento em uma escola de moda e a continuidade na prestação de serviços de consultoria. Já Palomino (2019) diz que entrou como

designer em uma indústria da estamparia. Dois anos e algumas especializações depois, fui convidado para gerenciar as coleções dessa empresa. Dali em diante foram mais dois degraus para chegar a gerente de pesquisa e desenvolvimento e diretor de criação e inovação. Sete anos depois de formado, abri meu próprio 
estúdio de artes para estamparia em uma tentativa de diminuir o ritmo para um nível saudável. Depois de dois anos de desenvolvimento, hoje somos um humilde fornecedor de artes "tropicais" para estúdios italianos que atendem Diesel, D\&G, Moschino e outras marcas de menor renome. (PALOMINO, 2019)

De fato, esses relatos obtidos nos questionários corroboram os esforços do Estado de Santa Catarina no desenvolvimento de cadeias de relacionamento têxteis e culturais e do empreendedorismo. 0 egresso Kalil (2019), igualmente, declara sua trajetória de ascensão e empreendedorismo:

No início da faculdade, eu trabalhava na Colcci, porém na engenharia de produto. Logo nos primeiros períodos, surgiu uma vaga na Hering onde comecei a desenvolver produtos infantis. Em pouco tempo, fui trocada para a área de pijamas e por causa do meu TCC, sobre a Campanha do Câncer de Mama, no qual relatei toda a história e desenvolvi uma coleção que teve ótima aceitação, pude ir para o setor feminino de desenvolvimento. A partir daí, com a transferência para São Paulo tive mais contado com gerenciamento de pessoas e de marca. Depois de nove anos na empresa, voltei para gerenciar as marcas da malharia Cristina, e saí para montar uma loja especializada em moda gestante, a Koisas de Mãe. Apesar de não desenvolver muito, a área de varejo e compra de coleção também é bastante desafiadora. A loja completa nove anos em setembro de 2019. Paralelo a isso, faço freelas de desenvolvimento infantil. (KALIL, 2019)

Em outro relato, o egresso Coelho (2019) relata sua experiência profissional e o empreendimento em serviços:

Ainda na universidade, consegui emprego em uma empresa de jeans de médio porte, trabalhando com desenvolvimento de coleções e modelagens em sistema CAD. Depois trabalhei por seis meses na Cia. Hering, na divisão tecido plano somente na modelagem -, sistema CAD. Mais tarde, fui funcionária da Luli Malhas, setor de criação e modelagem - sistema CAD. Desde 2001, tenho uma sócia (também formada em Moda) e, no início, fazíamos desenvolvimento de coleções e modelagens para empresas de pequeno e médio portes. Atualmente, desenvolvemos somente modelagens - sistema CAD. (COELHO, 2019)

O entrevistado Bündchen (2019) relata um processo diferente ao dizer que ascendeu em diversidade de campos de atuação, inicialmente como "estilista", depois como "gerente de marketing e moda", só então passou a ser "consultora de moda e estilo" independente até se tornar "professora de Desenho de Moda".

Observamos, dessa forma, que a trajetória profissional dos egressos que responderam ao questionário mostra-nos a experimentação pelas áreas e a atuação em serviços, MEI, varejo e em educação, revelando a ramificação e a diversidade dos campos de atuação em moda. A partir desses relatos, pudemos compreender que não há como pensar em um curso de moda que se constitua apenas de uma ou de outra organização de conhecimentos, senão de uma multiplicidade deles. 
Além disso, foi possível observar as transformações no mundo do trabalho na trajetória profissional dos egressos, assim como os desafios de um cenário de conhecimentos globalizados, transnacionalizados e internacionalizados (ANTUNES, 2015). Ao verificar os campos de atuação descritos no Projeto de Viabilidade do Curso, por exemplo, alguns deles têm relação com os campos de atuação citados pelos egressos respondentes, como mostra a figura 1.

\title{
FIGURA 1 - RELAÇÕES ENTRE OS CAMPOS DE ATUAÇÃO DO PROJETO DO CURSO E OS DOS EGRESSOS
}
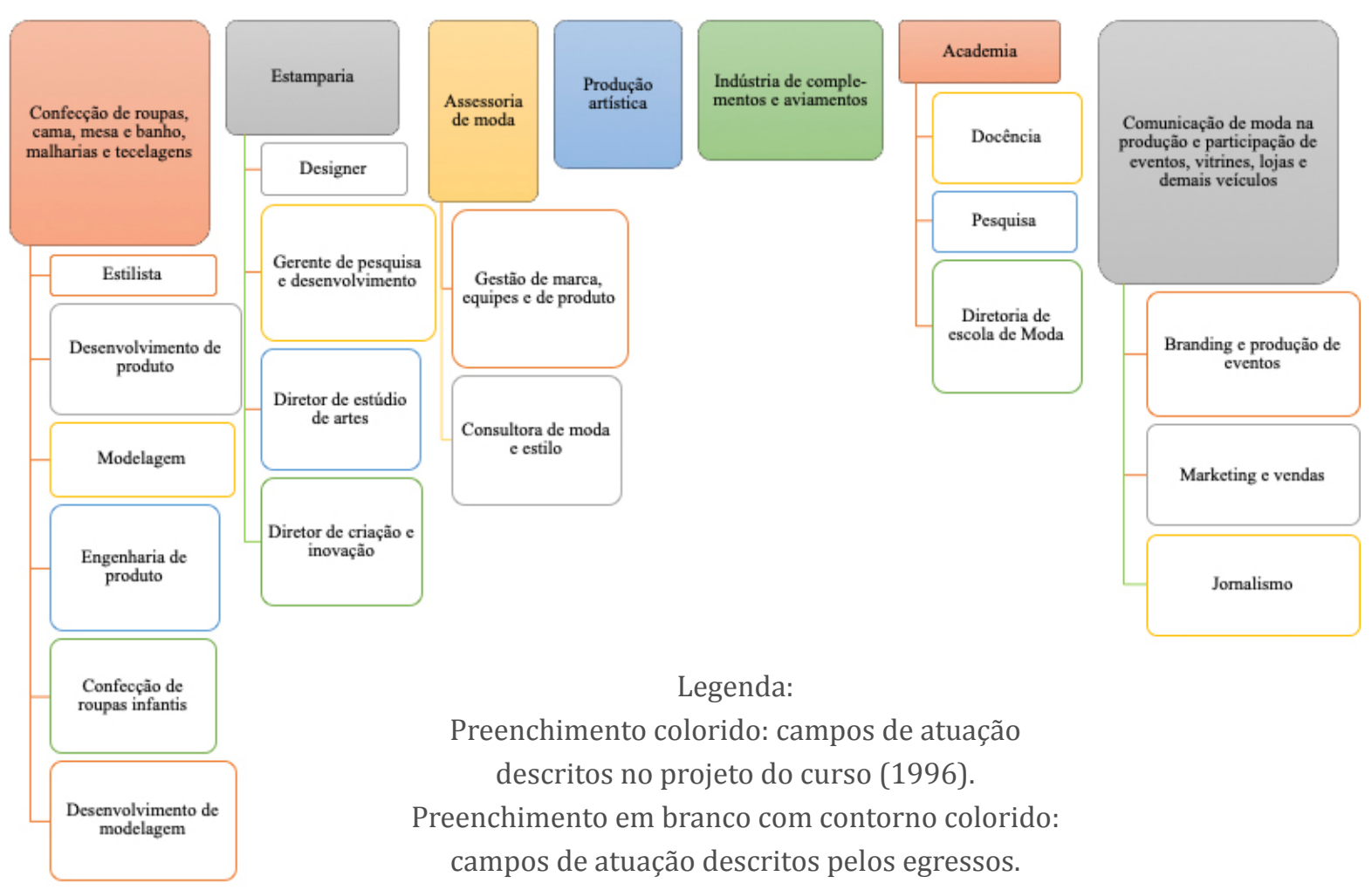

\author{
Legenda: \\ Preenchimento colorido: campos de atuação \\ descritos no projeto do curso (1996). \\ Preenchimento em branco com contorno colorido: \\ campos de atuação descritos pelos egressos.
}

FONTE: Elaborada pela autora (2019).

Na amostragem desta pesquisa não foram encontradas relações entre a produção artística de moda e a indústria de complementos. Em Santa Catarina, há pequenas empresas de produção artística para teatro, televisão, dança, cinema, jornalismo, circo e comunicação. Apenas Blumenau tem 244 agentes de cultura cadastrados e nove espaços específicos das áreas listadas, nos quais seria possível atuar com produção de moda, styling, fotografia, artes gráficas e digitais, pesquisa, desenvolvimento, produção de figurino, entre outras.

Nenhum desses campos de atuação foi citado pelos egressos respondentes. Segundo eles, os empregos existentes eram essencialmente fabris. Foram relatadas dificuldades no acesso a trabalhos criativos, o que nos permite deduzir que esses agentes e espaços criativos cadastrados na plataforma não fazem parte do percurso profissional deles.

Além disso, havia um número considerável de indústrias de complementos do vestuário em Blumenau, e no Rio Grande do Sul existia um polo de complementos em metais do vestuário, indicando uma ênfase curricular do curso de Moda estudado no vestuário. Foi 
possível perceber, a partir dos relatos obtidos, que a atuação em desenvolvimento de coleção foi um ponto em comum para maior parte deles, já o desenvolvimento de estamparia foi exercido unicamente pelo egresso Palomino (2019). A falta de relação entre o desenvolvimento de superfície e o desenvolvimento de coleção feita por Palomino (2019) traz à tona uma questão conceitual, a da relação substancial dada ao processo de desenvolvimento de coleção de roupas em detrimento de outras práticas, como marketing, gestão, criação, pesquisa e empreendedorismo.

Assim, no que se refere à pesquisa científica, observamos que foi acessado apenas pelo entrevistado Zuzu (2019), que relatou ter cursado mestrado e doutorado. Além de diversificada, a trajetória formativa e profissional dos egressos de 2001, no geral, demonstrou-se internacionalizada tanto para a formação complementar quanto no acesso aos campos de atuação.

\section{Considerações finais}

Esta pesquisa teve como objetivo principal compreender o currículo de Moda e suas relações com a atuação profissional a partir da análise de um questionário aplicado aos egressos de 2001 de um curso de bacharelado em Moda de uma universidade pública da cidade de Blumenau, em Santa Catarina. A caracterização curricular permitiu-nos perceber que o currículo estava alinhado às demandas profissionais do setor industrial local, com maior ênfase no sistema produtivo têxtil-vestuarista fabril, na criação, na cultura e na linguagem de moda.

Dessa maneira, o currículo da graduação teve como contexto histórico as políticas de colonização e de desenvolvimento de Santa Catarina, assim como recebeu influências do conceito de moda do vestuário vivido no Brasil, as quais tomamos como indicadores que perpassaram a formação do curso e o percurso dos egressos, como as políticas econômicas e educacionais da década de 1990 e a globalização. Nesse período de construção do projeto foi identificada a falta de profissionais formados em Moda com titulação necessária para preencher o quadro de professores, uma das exigências para regulamentação do programa.

Os campos de atuação acessados pelos egressos após a conclusão do bacharelado foram semelhantes aos citados no Projeto do Curso de Moda analisado, no entanto, a diversificação dos arranjos produtivos e dos modelos de negócios durante o século XXI, que foi percebida nos excertos retirados do questionário aplicado aos mesmos profissionais, exigiu deles formação complementar em setores da moda relacionados com sistemas produtivos diferenciados, bem como em outros setores como marketing, pesquisa científica, comunicação e criatividade. Durante a trajetória dos egressos, observamos que o sistema capital seguiu suas transformações adentrando em economias semiperiféricas e fomentando as morfologias do mundo do trabalho. Podemos entender essas morfologias como as mudanças estruturais que ocorrem, de forma mais visível, com a globalização, a partir da década de 1980 no Brasil. Dessas transformações, podemos citar o desemprego, a desarticulação da classe-que-vive-do-trabalho, a perda de poder dos sindicatos e, para os profissionais de moda, podemos elencar as características multifacetadas do trabalho, a concorrência global que ampliou a necessidade de saberes culturais, bem como a criação da identidade da moda nacional - o que exigiu deles cada vez mais conhecimento. 
A corrida pela profissionalização do setor fabril foi uma forma de acompanhar as nações primariamente industrializadas. Nesse contexto, vimos emergir das morfologias do mundo do trabalho a diversidade de campos de atuação e, por causa dessa variedade, entende-se a dificuldade para garantir uma formação curricular dos cursos de Moda, os quais costumam se orientar por demandas profissionais locais e, assim, muitas vezes optam por modelos de negócios, como no caso do curso analisado.

Dessa maneira, a escolha pelo modelo produtivo industrial, que se estabeleceu durante a década de 1990 no Brasil como fast fashion, identificada na análise da proposta curricular, permitiu o conceito de moda do vestuário, concepção comum no século XX, conforme aborda Trevisol Neto (2015). Este se aplicou ao contexto prático existente, satisfazendo as demandas profissionais da indústria têxtil- vestuarista da região do Vale do Itajaí.

A partir dos dados levantados, observamos que o profissional de moda se transformou em um especialista multitarefas com o intuito de satisfazer o sistema de moda. Nesse esse ponto, esta pesquisa colheu informações que nos permitem questionar a escolha de um curso de Moda por causa de um único modelo de negócios, como o fast fashion. As relações construídas pelos egressos entre a formação inicial e sua trajetória, em seus campos de atuação, demonstrou indicadores históricos que atravessam seus percursos mostrando um mundo do trabalho em constante transformação, nos quais os modelos de negócios igualmente se alteram à medida que se modificam os arranjos produtivos.

Importa-nos ainda salientar que a moda nasce global e ainda pode ser caracterizada por acompanhar as transformações sociais em tempo real. Dessa forma, compete-nos, como pesquisadores, questionar em que passo a universidade no Brasil acompanha o mundo do trabalho, ouvindo a voz daqueles que nele se estabelecem e mesmo a dos que não conseguem se firmar. No que concerne aos cursos de Moda no Brasil, é preciso pensar em uma formação local voltada para um mundo de trabalho globalizado, considerando as características da própria área.

Assim, pela caracterização do currículo de Moda aqui apresentada, pelo percurso formativo, pela trajetória profissional dos egressos e das relações constituídas entre o currículo do bacharel em Moda e os campos de atuação dos profissionais entrevistados, esperamos ter contribuído com esta pesquisa e que venham outras na busca por uma compreensão dos currículos dos cursos de Moda no Brasil, propondo uma formulação baseada nas novas morfologias do mundo do trabalho e nas reformulações do setor e do conceito de moda brasileira. 


\section{Referências}

ANTUNES, Ricardo. Adeus ao trabalho? Ensaio sobre as metamorfoses e a centralidade do mundo do trabalho. 3. ed. São Paulo: Cortez, 1995.

ANTUNES, Ricardo. Adeus ao trabalho? Ensaio sobre as metamorfoses e a centralidade do mundo do trabalho. 16. ed. São Paulo: Cortez, 2015.

BALTAR, Paulo Eduardo de Andrade. Estrutura econômica e emprego urbano na década de 1990. In: PRONI, Marcelo Weishaupt; HENRIQUE, Wilnês (org.). Trabalho, mercado e sociedade: o Brasil nos anos 90. Campinas: Editora Unesp, 2003. p. 107-152.

BARDIN, Laurence. Análise de conteúdo. 3. Reimpressão. São Paulo: Edições 70, 2016.

BAUDRILLARD, Jean. A sociedade de consumo. Rio de Janeiro: Elfos, 1995.

BAUMAN, Zygmunt. A sociedade individualizada. Vidas contadas e histórias vividas. Trad. José Gradel. 2. ed. Rio de Janeiro: Zahar, 2008.

BONADIO, Maria Claudia; MARINHO, Maria Gabriela; WAJNMAN, Solange. Apresentação Dossiê Moda e Conhecimento: interfaces com as ciências humanas e a comunicação. Iara, São Paulo, v. 3, n. 3, 2010. Disponível em: http://www1.sp.senac.br/hotsites/blogs/revistaiara/ index.php/vol-3-no3-ano-2010/. Acesso em: 22 out. 2019.

BORGES, Márcia de Souza; LIMA, Rita de Cássia Pereira. Representações sociais de alunos e professores do curso de Design de Moda sobre a Moda. In: MATTOS, Maria de Fátima da Silva Costa Garcia (org.) Pesquisa e formação em Moda. São Paulo: Estação das Letras e Cores, 2015. p. 103-133.

BORGES, Marcia de Souza. Problematizando a formação superior em Moda. dObra[s], São Paulo, v. 10, n. 21, 2017. Disponível em: https://dobras.emnuvens.com.br/dobras/article/ view/557. Acesso em: 4 out. 2019.

BRASIL. Ministério da Cultura. Decreto n. 7.566. Rio de Janeiro, 23 de setembro de 1909. Disponível em: http://portal.mec.gov.br/setec/arquivos/pdf3/decreto_7566_1909.pdf. Acesso em: 9 set. 2019.

BRASIL. Ministério da Cultura. Programa cultural para o desenvolvimento do Brasil. Brasília: MinC, 2006a. Disponível em: http://rubi.casaruibarbosa.gov.br/ bitstream/20.500.11997/6837/1/119.pdf. Acesso em: 9 set. 2019. 
BRASIL. Lei Complementar n. 123 de 14 de dezembro de 2006. Institui o Estatuto Nacional da Microempresa e da Empresa de Pequeno Porte; altera dispositivos das Leis n. 8.212 e 8.213, ambas de 24 de julho de 1991, da Consolidação das Leis do Trabalho CLT, aprovada pelo Decreto-Lei n. 5.452, de $1^{\circ}$ de maio de 1943, da Lei n. 10.189, de 14 de fevereiro de 2001, da Lei Complementar n. 63, de 11 de janeiro de 1990; e revoga as Leis n. 9.317, de 5 de dezembro de 1996, e 9.841, de 5 de outubro de 1999 (VER - DO ACESSO AOS MERCADOS, Seção Única - Das Aquisições Públicas - Capitulo V). Brasília, DF, 14 dez. 2006b. Disponível em: http://www.comprasnet.gov.br/legislacao/leis/lei123_2006.htm. Acesso em: 19 nov. 2019.

BRASIL. Ministério da Cultura. 2013a. Programa cultural para o desenvolvimento do Brasil. Brasília: Centro de Gestão e Estudos Estratégicos - CGEE, 2006. Disponível em: http://rubi.casaruibarbosa.gov.br/bitstream/20.500.11997/6837/1/119.pdf. Acesso em: 13 maio 2020.

BRASIL. Ministério da Cultura. Plano Cultural da Moda. Brasília: Ismália Afonso, SPC/MinC, 2013b. Disponível em: https://bit.ly/2PdCzkh. Acesso em: 9 set. 2019.

CIDREIRA, Renata Pitombo. A moda como expressão cultural e pessoal. IARA, São Paulo, v. 3, n. 3, 2010, p. 228-244. Disponível em: http://www1.sp.senac.br/hotsites/blogs/revistaiara/ wp-content/uploads/2015/01/07_IARA_vol3_n3_Dossie.pdf. Acesso em: 13 maio 2020.

CMU. Centro de Memória Universitária. Currículo pleno do curso de bacharelado em Moda. Cód.: 97.2.042-0/1997. Blumenau: CMU, 1997.

COMO, Giancarlo Conti. 0 design da seda. Itália: La Tessitura, 2005.

COORDENADOR. Entrevista com coordenador do curso de Moda. [Entrevista concedida a] Emanuella Scoz. FURB, 2019.

DELGADO, Daniela. Configurações sobre a educação no setor de Moda. IARA, São Paulo, v. 3, n. 3, 2010, p. 147-169. Disponível em: http://www1.sp.senac.br/hotsites/blogs/revistaiara/ wp-content/uploads/2015/01/04_IARA_vol3_n3_Dossie.pdf. Acesso em: 13 maio 2020.

GUIMARÃES, Maria Eduarda Araújo. Moda, cultura e identidades. In: ENECULT - ENCONTRO DE ESTUDO MULTIDISCIPLINARES EM CULTURA, 4. ed., 2008, Salvador. Anais [...]. UFBA: Salvador, 2008. Disponível em: http://www.cult.ufba.br/enecult2008/14326.pdf. Acesso em: 19 nov. 2019.

HALL, Stuart. Cultura e representação. Trad. Daniel Miranda e William Oliveira. Rio de Janeiro: Aícuri; PUC-Rio, 2016. 
KOHLHEPP, Gerd. A indústria sul-brasileira na fase da globalização: caso do desenvolvimento econômico regional no Nordeste de Santa Catarina. Revista del Cesla, n. 11, 2008, p. 207224. Disponível em: https://www.redalyc.org/articulo.oa?id=243316550014. Acesso em: 23 out. 2019.

LIMA, Gisele Matos; MORAES, Mario César Barreto. Os conteúdos de administração nos cursos de moda de Santa Catarina. In: COLÓQUIO DE MODA, 9. ed., 2013, Fortaleza. Anais [...]. Fortaleza: UFCE, 2013. Disponível em: http://www.coloquioModa.com.br/anais/ Coloquio\%20de\%20Moda\%20-\%202013/COMUNICACAO-ORAL/EIXO-2-EDUCACAO_ COMUNICACAO-ORAL/Os-conteudos-de-Administracao-nos-Cursos-de-Moda-de-SantaCatarina.pdf. Acesso em: 4 out. 2019.

MATTOS, Maria de Fátima da Silva Costa Garcia (org.) Pesquisa e formação em Moda. São Paulo: Estação das Letras e Cores, 2015.

MEYER-STAMER, Jörg. Algumas observações sobre clusters em Santa Catarina. Atualidade Econômica, Florianópolis, ano 12, n. 37, 2000, p. 5-7. Disponível em: https://cnm.ufsc.br/ files/2013/09/boletim-37.pdf. Acesso em: 13 maio 2020.

PERFIL DA ALEMANHA. Sinopse dos fatos, 2018. Disponível em: https://www.tatsachenueber-deutschland.de/pt-br/download-de-pdf-e-documento-digitais. Acesso em: 9 set. 2019.

PCD. Secretaria do Planejamento do Estado de Santa Catarina. Plano catarinense de desenvolvimento 2015. Florianópolis: SPSC, 2006. Disponível em: http://www.spg. sc.gov.br/visualizar-biblioteca/acoes/plano-catarinense-de-desenvolvimento/402-planocatarinense-desenvolvimento/file. Acesso em: 9 set. 2019.

PROJETO. Projeto de viabilidade e autorização do curso de Bacharelado em Moda Habilitação em Estilismo Industrial. Blumenau: Instituição, 1996.

SACRISTÁN, José Gimeno. 0 currículo. Uma reflexão sobre a prática. Trad. Ernani F. da Fonseca Rosa. 3. ed. Porto Alegre: Artmed, 2000.

SANCHES, Lucinéia. Os moldes da moda: um estudo sobre o estado dos cursos de formação em Moda no Brasil. 2006. 121 f. Dissertação (Mestrado em Educação) - Universidade Regional de Blumenau, Blumenau, 2006.

SANT'ANNA, Mara Rubia. Costuras narrativas de um passado recortado pelo presente. In: MAKOWICCKY, Sandra; OLIVEIRA, Sandra Ramalho; COLLAÇO, Sandra. Centro de Artes da UDESC. História, imagens e memórias. Florianópolis: UDESC, 2018. p. 219-239.

SANT'ANNA, Mara Rúbia. Teoria da Moda - Sociedade, Imagem e Consumo. 2. ed. 3. reimpressão. São Paulo: Estação das Letras e Cores, 2016. 
SANTOS, Boaventura de Souza (org.). A globalização e as ciências sociais. São Paulo: Cortez, 2002.

SEBRAE. Perfil do microempreendedor individual 2015. Brasília: SEBRAE, 2016. Disponível em: http://www.sebrae.com.br/Sebrae/Portal\%20Sebrae/Anexos/Perfil\%20 do\%20MEI\%202015.pdf. Acesso em: 9 set. 2019.

SEBRAE. Panorama SEBRAE. Brasília: SEBRAE, 2018. Disponível em: http://datasebrae.com. br/wp-content/uploads/2018/02/Panorama-Sebrae_012018.pdf. Acesso em: 9 set. 2019.

SENAI. História. Brasília: SENAI, 2018. Disponível em: http://www.portaldaindustria.com. br/senai/institucional/historia. Acesso em: 9 set. 2019.

SILVA, Bárbara Cravo da; NASCIMENTO, Luís Cláudio Portugal. Apontamentos acerca da integração entre conteúdos de Design e de Moda no percurso de implementação do Design de Moda. Projética, Londrina, v. 3, n. 1, 2012, p. 110-118. Disponível em: http://www.uel. br/revistas/uel/index.php/projetica/article/view/12266/11334. Acesso em: 19 nov. 2019.

TREVISOL NETO, Orestes. A institucionalização científica do campo da Moda no Brasil: estudo baseado nas instituições, produtores e produtos científicos. 2015. 191 f. Dissertação (Mestrado em Ciência da Informação) - Universidade Federal de Santa Catarina, Florianópolis, 2015. Disponível em: https://repositorio.ufsc.br/xmlui/bitstream/ handle/123456789/135394/334677.pdf?sequence=1\&isAllowed=y. Acesso em: 19 nov. 2019. 